\title{
A Convenient Colorimetric Bacteria Detection Method Utilizing Chitosan-Coated Magnetic Nanoparticles
}

\author{
Thao Nguyen Le, Tai Duc Tran and Moon Il Kim * (B) \\ Department of BioNano Technology, Gachon University, 1342 Seongnamdae-ro, Sujeong-gu, Seongnam, \\ Gyeonggi 13120, Korea; thaonguyen65949@gmail.com (T.N.L.); tdtai.151294@gmail.com (T.D.T.) \\ * Correspondence: moonil@gachon.ac.kr; Tel.: +82-31-750-8563
}

Received: 13 December 2019; Accepted: 31 December 2019; Published: 2 January 2020

\begin{abstract}
An effective novel strategy to detect bacteria is promising because it may improve human health by allowing early diagnosis and timely treatment of bacterial infections. Here, we report a simple, reliable, and economical colorimetric assay using the peroxidase-like activity of chitosan-coated iron oxide magnetic nanoparticles (CS-MNPs). When CS-MNPs are incubated with a sample containing bacterial cells such as the gram-negative Escherichia coli or the gram-positive Staphylococcus aureus, the negatively-charged bacterial membrane interacts with positively-charged chitosan on the surface of CS-MNPs, thus resulting in significant reduction of their peroxidase-like activity presumably by a hindrance in the accessibility of the negatively charged substrate, 2-2'-azino-bis(3-ethylbenzothiazoline-6-sulfonic acid) diammonium salt (ABTS) to the positively-charged CS-MNPs. This simple colorimetric strategy allowed the rapid detection of bacterial cells down to $10^{4} \mathrm{CFU} \mathrm{mL} \mathrm{m}^{-1}$ by the naked eye and $10^{2} \mathrm{CFU} \mathrm{mL} \mathrm{L}^{-1}$ by spectrophotometry within $10 \mathrm{~min}$. Based on the results, we anticipate that the CS-MNPs-based assay has great potential for the on-site diagnosis of bacterial infections in facility-limited or point-of-care testing (POCT) environments.
\end{abstract}

Keywords: colorimetric bacteria detection; chitosan-coated magnetic nanoparticles; peroxidase-like activity; Escherichia coli; Staphylococcus aureus

\section{Introduction}

Bacterial contamination in myriad environments has become a serious threat to human life as it can cause various diseases. Among many pathogenic bacteria in water, food, or pharmaceutical products, gram-negative Escherichia coli and gram-positive Staphylococcus aureus are two major bacterial species causing disease including diarrhea, anemia, skin infections, orbital cellulitis, urinary tract infections, and eventually death [1-3]. According to the World Health Organization (WHO), infectious diseases by food-borne pathogenic bacteria caused 240,000 deaths globally in 2010. Considering the seriousness of bacterial contamination, a simple, rapid, reliable, sensitive, and early-screening method to detect bacteria is critically important to conduct early-diagnosis as well as timely treatment to effectively prevent and cure the disease [4].

There are many methods for bacteria detection. The plate colony counting method is considered as a "gold standard" because it provides a direct enumeration of bacteria through cultivation under standard conditions. However, it inevitably requires specific facilities for microbial cell cultivation and skilled personnel, as well as a long-time analysis of up to several days for enrichment, plating and isolation, and identification [5]. Other techniques including polymerase chain reaction (PCR) and immunological methods such as enzyme-linked immunosorbent assay (ELISA) have been widely used for bacterial detection based on their ability to overcome such time limitations with high detection sensitivity and selectivity. However, these methods are conducted with specialized instruments, complicated sample treatment and analytic procedures, and well-trained individuals with the appropriate expertise. 
More importantly, these methods cannot be conducted on-site, critically restricting their use in limited facilities or point-of-care testing (POCT) environments [6,7].

To develop bacteria detection methods particularly suitable for on-site detection, colorimetric techniques have attracted increasing attention due to their easy operation and visual detection without any instrumentation/expertise [8,9]. Several enzymatic assays have been reported for the colorimetric detection of bacteria, for example, T7 bacteriophages carrying the lacZ operon were used to infect $E$. coli, allowing the overexpression of lacZ-dependent $\beta$-galactosidase to catalyze a colorimetric reaction depending on the amount of E. coli [10]. Glucose oxidase-mediated colorimetric detection methods were also reported for broad-spectrum bacteria carrying out glucose metabolism [11]. These enzymatic methods provide simple colorimetric identification of bacteria, however, specific biological elements like phage-induced systems are often difficult to apply for broad-spectrum bacteria detection. Also, enzyme instability has significantly hindered its practical utilization.

To overcome these limitations, diverse nanomaterials such as nanoparticles, nanorods, nanowires, and carbon nanostructures have been used because of their excellent physicochemical properties [12,13]. Noble metal nanoparticles such as those composed of gold and silver have been investigated based on their unique optical properties inducing a distinct color change by aggregation or chemical reaction on their surface [14,15]. They produce a rapid and sensitive colorimetric response to target bacteria, however, they generally require laborious surface modification with biomolecules such as DNA, RNA, and antibodies, and are often quite sensitive to experimental conditions causing false positives. Several peroxidase-mimicking nanomaterials including gold nanoparticles, graphene oxide, and iron oxide magnetic nanoparticles (MNPs) were also explored for the specific detection of pathogenic bacteria, as they exhibit noticeable enzyme activity with extremely high stability and they can be mass-produced at low cost [16-18]. Like natural peroxidase, these nanomaterials can decompose $\mathrm{H}_{2} \mathrm{O}_{2}$ into an $\mathrm{OH}$ - radical that can oxidize peroxidase substrates such as $3,3^{\prime}, 5,5^{\prime}$-tetramethylbenzidine (TMB) or 2-2'-azino-bis (3-ethylbenzothiazoline-6-sulfonic acid) diammonium salt (ABTS) yielding blue and green color, respectively $[18,19]$. Typically, pathogen-specific receptors like antibodies or DNA aptamers are conjugated on the surface of the nanomaterials and they are used to detect bacteria via sandwich-type assay procedures $[20,21]$. Several reports demonstrated that the sandwich-type colorimetric assay is successful to detect bacterial cells, however, it requires tedious surface modification steps as well as many experimental procedures [22-24]. A label-free detection method using MNPs was also recently reported. In the assay, DNA aptamer molecules that have a specific affinity for Salmonella typhimurium were first adsorbed onto the surface of MNPs by electrostatic interaction resulting in the inhibition of the peroxidase-like activity of the MNPs [25]. Through the addition of sample solutions containing target $S$. typhimurium, aptamers bound on MNPs strongly interact with bacteria and are detached from the MNPs, thereby increasing their peroxidase activity. Using this strategy, target S. typhimurium is detected through observing the green color from the oxidation of the ABTS substrate; however, its sensitivity is too low and the limit of detection is $7.5 \times 10^{4}$ colony-forming unit (CFU) $\mathrm{mL}^{-1}$, presumably due to the insufficient control of the aptamer affinity between MNPs and bacterial cells [25]. Therefore, it is desirable to elaborately control the peroxidase activity of MNPs depending on the number of bacterial cells, to achieve higher sensitivity for practical on-site colorimetric detection.

Herein, we used chitosan, a polycationic biopolymer containing abundant amine groups in its backbone, to modify the surface of MNPs (CS-MNPs). Positively charged chitosan has been proven to show a high affinity toward broad-spectrum bacteria, majorly due to the negative surface charge as well as outer-core lipopolysaccharides of the bacterial membrane [26]. Based on the high affinity of chitosan toward broad-spectrum bacteria, we hypothesized that bacterial cells would effectively bind to CS-MNPs, thereby inhibiting their peroxidase-like activity, which would produce a decreased colorimetric response. Gram-negative E. coli and gram-positive S. aureus were successfully determined at $10^{4} \mathrm{CFU} \mathrm{mL} \mathrm{m}^{-1}$ by the naked eye and at $10^{2} \mathrm{CFU} \mathrm{mL} \mathrm{m}^{-1}$ by spectrophotometry within $10 \mathrm{~min}$. Scanning electron microscopy (SEM) and zeta potential analyses were used to understand the binding mechanism between CS-MNPs and the bacterial cells. 


\section{Experimental Section}

\subsection{Materials}

Chitosan (CS), iron (III) chloride hexahydrate $\left(\mathrm{FeCl}_{3} \cdot 6 \mathrm{H}_{2} \mathrm{O}\right)$, iron (II) chloride tetrahydrate $\left(\mathrm{FeCl}_{2} \cdot 4 \mathrm{H}_{2} \mathrm{O}\right)$, sodium hydroxide, phosphate-buffered saline (PBS), ABTS, sodium acetate, hydrogen peroxide $\left(\mathrm{H}_{2} \mathrm{O}_{2} 30 \% w / v\right)$, acetic acid, ethanol, and glutaraldehyde $(25 \% w / v)$ were purchased from Sigma-Aldrich (Milwaukee, WI, USA). The Luria-Bertani (LB) broth and agar powder were purchased from Becton, Dickinson and Company (Franklin Lakes, NJ, USA). All solutions were prepared with deionized water purified with a Milli-Q Purification System (Millipore, MA, USA).

\subsection{Synthesis of MNPS and CS-MNPS}

MNPs were synthesized using a reported co-precipitation method [27]. Briefly, 1 M sodium hydroxide was added to the aqueous mixture of $0.25 \mathrm{M} \mathrm{FeCl}_{2}$ and $\mathrm{FeCl}_{3}\left(\mathrm{Fe}^{3+} / \mathrm{Fe}^{2+}=2\right)$ until $\mathrm{pH}$ turned 10. Then, the mixture was heated at $80^{\circ} \mathrm{C}$ for $40 \mathrm{~min}$ under stirring until color changed from bright brown to black. The black precipitates were washed several times with deionized water and ethanol to remove salt residues. The resulting MNPs were dried under vacuum at $70{ }^{\circ} \mathrm{C}$ overnight.

MNP surfaces were coated with chitosan to produce CS-MNPs as follows: MNPs (50 mg) were dispersed in distilled water $(50 \mathrm{~mL})$ under sonication for $30 \mathrm{~min}$ followed by a slow addition of $2 \%$ $w / v$ chitosan solution in $1 \% v / v$ acetic acid while stirring at $1000 \mathrm{rpm}$ at $50{ }^{\circ} \mathrm{C}$. After $12 \mathrm{~h}$ reaction, the resulting CS-MNPs were collected by magnetic separation after multiple rinses using water and ethanol to remove free chitosan. The resulting CS-MNPs were dried at $60{ }^{\circ} \mathrm{C}$ under vacuum overnight [28].

\subsection{Characterization of MNPs, CS-MNPs, and Bacteria with Nanoparticles}

The size, morphology, and elemental composition of MNPs and CS-MNPs were analyzed by SEM images on a Magellan 400 microscope (FEI Co., Eindhoven, The Netherlands) and an energy dispersive X-ray spectrometer (EDS). Nanoparticle samples for SEM were prepared by placing a drop of suspension on a polished wafer and dried overnight at room temperature. Zeta potential analysis was carried out using a Zetasizer Nano-ZS (Malvern Co., Worcestershire, UK). Fourier-transform infrared (FT-IR) spectra and X-ray diffraction (XRD) patterns of MNPs, CS-MNPs, and free chitosan were obtained using an FT-IR spectrophotometer (FT/IR-4600, JASCO, Easton, MD, USA) and an X-ray diffractometer (D/MAX-2500, Rigaku Corporation, Tokyo, Japan), respectively.

The interaction of MNPs and CS-MNPs with E. coli or S. aureus was also analyzed by SEM and zeta potential analysis. For SEM, bacteria were first grown in LB media to log phase $\left(\mathrm{OD}_{600 \mathrm{~nm}} \sim 0.6\right)$. Then, bacterial cells were centrifuged at $8000 \mathrm{rpm}$ for $3 \mathrm{~min}$, washed several times with PBS, and serially diluted in PBS to obtain $10^{5} \mathrm{CFU} \mathrm{mL}{ }^{-1}$ suspensions. The cells were treated with $200 \mu \mathrm{g} \mathrm{mL} \mathrm{MNPs}^{-1}$ CS-MNPs for $6 \mathrm{~h}$. After treatment, the mixture was centrifuged at $8000 \mathrm{rpm}$ for $3 \mathrm{~min}$ and rinsed twice with PBS. Subsequently, cells were fixed with $2.5 \%$ glutaraldehyde in PBS for $4 \mathrm{~h}$ and further rinsed twice in PBS. After fixation, cells were subjected to dehydration in a series of ethanol solutions with increasing concentrations $(20 \%, 30 \%, 40 \%, 50 \%, 60 \%, 70 \%, 80 \%, 90 \%$, and pure ethanol) for $10 \mathrm{~min}$ in each step. Finally, cells were added dropwise onto a silicon wafer and air-dried overnight for SEM analysis.

\subsection{Selected Bacteria and Culture Conditions}

E. coli WT3110 strain and S. aureus ATCC 25923 strain were used for the bacterial detection experiments. Bacteria were grown in LB medium at $37^{\circ} \mathrm{C}$ and $200 \mathrm{rpm}$ in a shaking incubator (SI-7820, Optima, Japan). Then, cultured bacteria were centrifuged at $8000 \mathrm{rpm}$ for $5 \mathrm{~min}$ and resuspended in deionized water for the colorimetric detection experiments. The number of bacteria was determined by colony counting on LB-agar plates after incubation for $24 \mathrm{~h}$ at $37^{\circ} \mathrm{C}$. 


\subsection{Colorimetric Bacteria Detection Using CS-MNPS}

A $1 \times 10^{9} \mathrm{CFU} \mathrm{mL} \mathrm{mL}^{-1}$ bacterial suspension was prepared and diluted to various concentrations. Colorimetric bacteria detection was carried out in transparent tubes or 96-well plates containing MNPs or CS-MNPs $\left(0.1 \mathrm{mg} \mathrm{mL}^{-1}\right), \mathrm{H}_{2} \mathrm{O}_{2}(2.5 \mathrm{mM})$, ABTS $(6 \mathrm{mM})$, and a bacterial cell suspension in sodium acetate buffer $(50 \mathrm{mM}, \mathrm{pH} 4.0)$ at different concentrations. After $10 \mathrm{~min}$, nanoparticles and bacterial cells were removed by centrifugation at 12,000 rpm for $5 \mathrm{~min}$. The supernatant solution was used to obtain images and the corresponding absorption spectra or absorption intensity at $417 \mathrm{~nm}$ on a microplate reader (Synergy H1, BioTek, VT, USA).

\section{Results and Discussion}

\subsection{Preparation and Structural Characterization of MNPs and CS-MNPs}

Because positively-charged chitosan has been known to present a high electrostatic affinity toward negatively-charged bacterial cell membranes, MNPs were first coated with chitosan to prepare CS-MNPs (Figure 1a). Chitosan was dissolved in acidic $\mathrm{pH}$ conditions for the protonation of its amine groups [29]. The morphology and size of the resulting MNPs and CS-MNPs were then analyzed by SEM images (Figure 1b,c). Both MNPs and CS-MNPs presented spherical shapes with a nearly-uniform diameter of around $30 \mathrm{~nm}$.

(a)
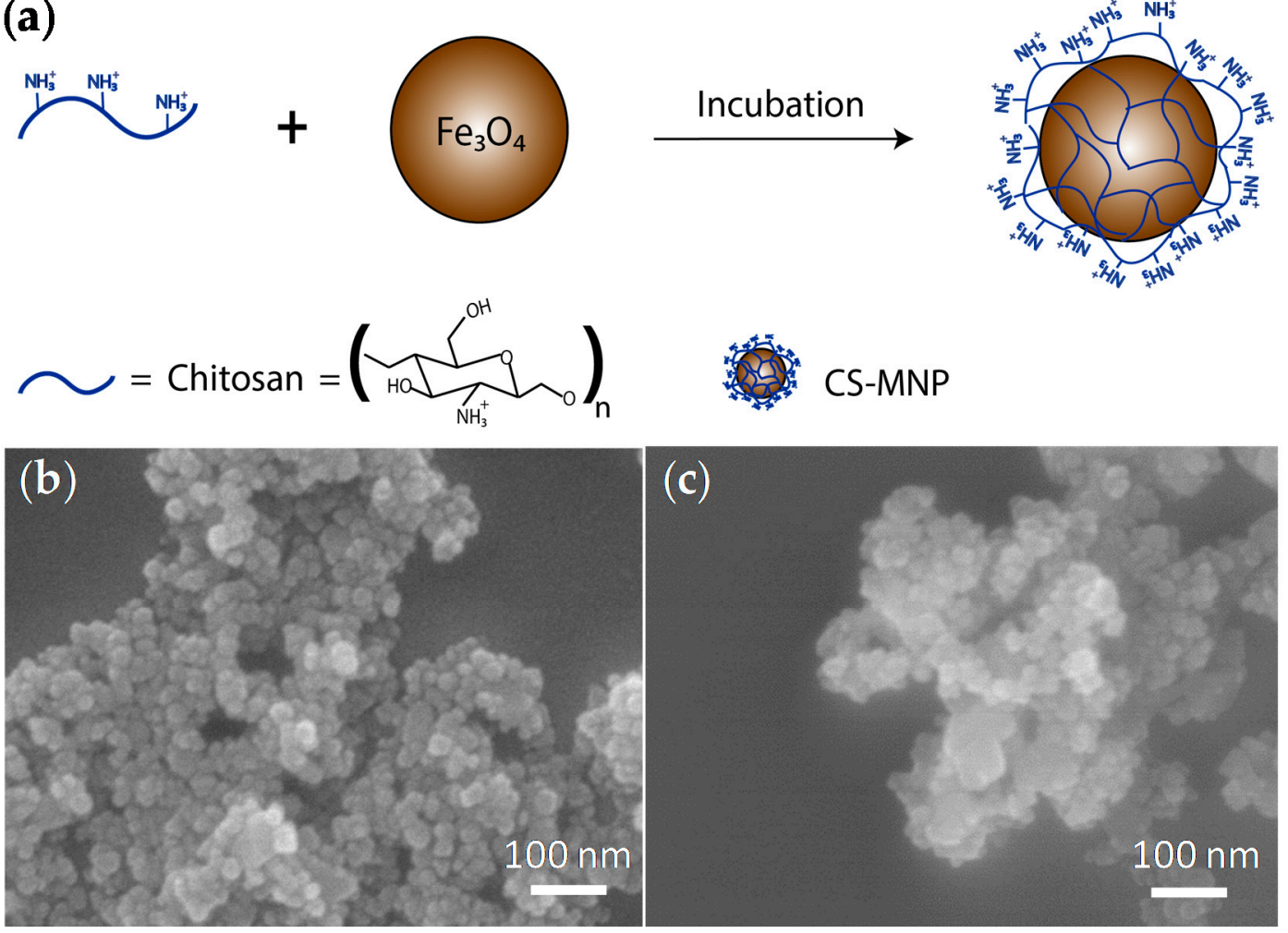

Figure 1. (a) Schematic illustration of chitosan coating the surface of iron oxide magnetic nanoparticles to prepare CS-MNPs. SEM image of (b) MNPs and (c) CS-MNPs.

For the bacterial detection experiments, the surface charge of bare MNPs was $+2.94 \mathrm{mV}$, and gradually increased as the concentration of chitosan also increased, as positively-charged chitosan has good adhesion to the hydroxyl group of MNPs (Figure S1) [30]. The SEM-EDS elemental mapping images of $\mathrm{Fe}, \mathrm{O}$, and $\mathrm{N}$ for CS-MNPs indicate the homogeneous distribution of each element throughout the aggregated nanoparticles, which are the main components of MNPs and chitosan (Figure 2a). In contrast, bare MNPs did not show any N, clearly revealing the absence of chitosan (Figure $2 b$ ). 
Chemical compositions were also confirmed by FT-IR analyses (Figure 2c). Typical characteristic peaks corresponding to the Fe-O bond were observed at $536 \mathrm{~cm}^{-1}$ for both MNPs and CS-MNPs, and furthermore, the peaks at about $3300-3340 \mathrm{~cm}^{-1}$ represent $\mathrm{O}-\mathrm{H}$ stretching vibration, demonstrating the presence of iron oxide nanoparticles [31]. For CS-MNPs, there were peaks at 1324 and $1432 \mathrm{~cm}^{-1}$ indicating C-N stretching, and $1533 \mathrm{~cm}^{-1}$ indicating the bending vibration of $\mathrm{NH}_{3}{ }^{+}$, clearly showing the presence of chitosan [32-34]. These characteristic peaks were not detected in MNPs because of the absence of chitosan. XRD patterns also showed six characteristic peaks for $\mathrm{Fe}_{3} \mathrm{O}_{4}$ crystal with the indices (220), (311), (400), (422), (511) and (440) (Figure 2d) [35]. The peaks detected at around $20^{\circ}$ for CS-MNPs are closely associated with chitosan.
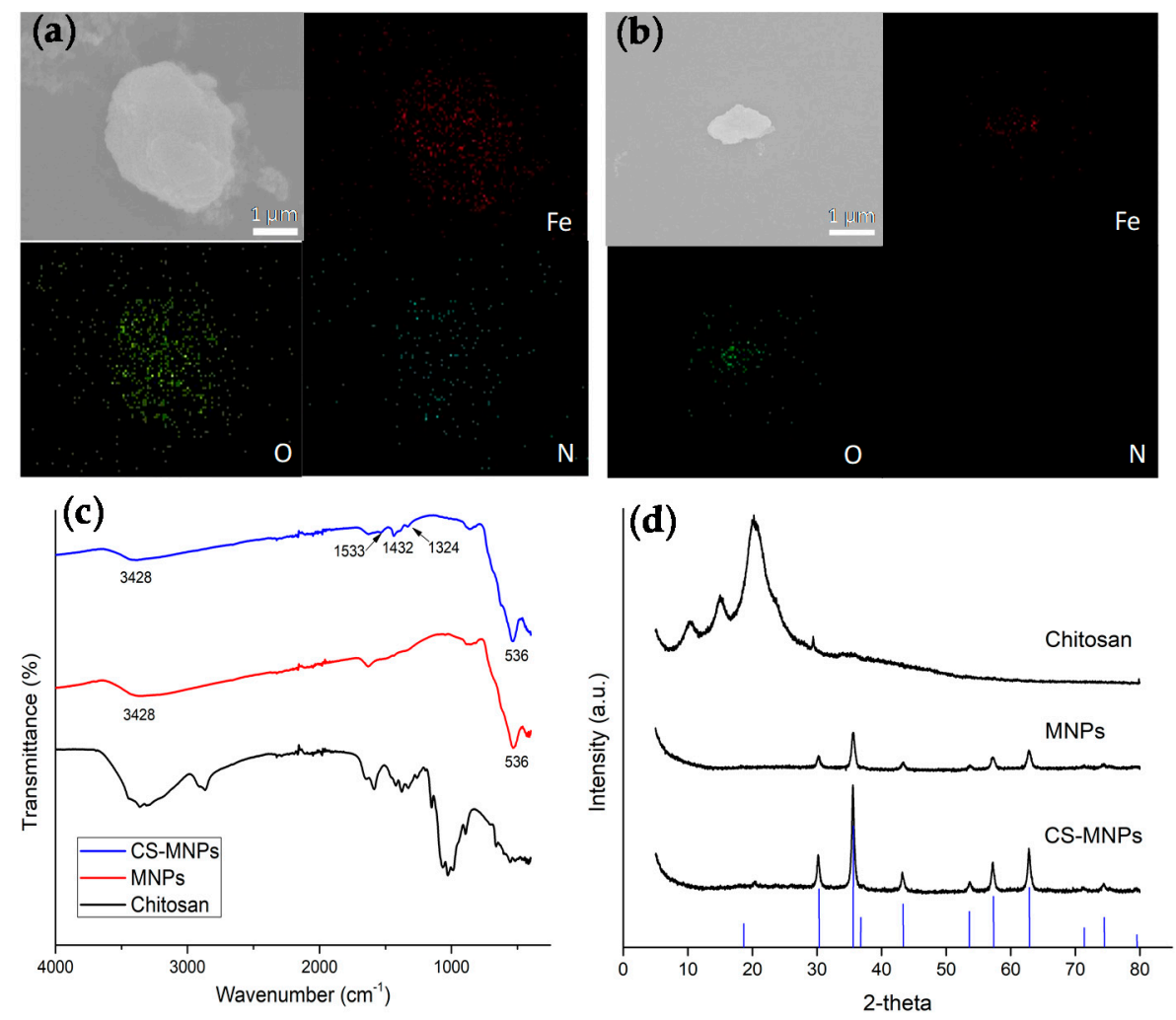

Figure 2. SEM images of (a) CS-MNPs and (b) MNPs with their corresponding EDS maps of Fe, O, and N. (c) FT-IR spectra and (d) XRD spectra for CS-MNPs, MNPs, and chitosan.

\subsection{Rapid and Sensitive Colorimetric Bacteria Detection Using CS-MNPS}

The novel colorimetric assay for the detection of broad-spectrum bacteria is illustrated in Figure 3. The procedure involved the simple incubation of CS-MNPs with a sample solution for just 10 min at room temperature to detect broad-spectrum bacteria. When there were no bacteria in the sample solution, CS-MNPs exhibited their original peroxidase-like catalytic activity and a dense green color from the oxidation of ABTS. On the contrary, in the presence of bacteria, CS-MNPs were bound to their surface through electrostatic interactions resulting in a decreased available surface area for catalytic events with increased hindrance in the accessibility of the negatively-charged ABTS to the positively-charged CS-MNPs and thereby leading to the reduced peroxidase-like activity of CS-MNPs. Overall, assay samples containing bacterial cells displayed significantly lowered colorimetric responses while those without bacteria produced an intense colorimetric response. As this color-generating reaction from the ABTS oxidation takes only $10 \mathrm{~min}$ at room temperature, we expect this assay to be used for rapid but effective detection of broad-spectrum bacteria on site. 
(a)
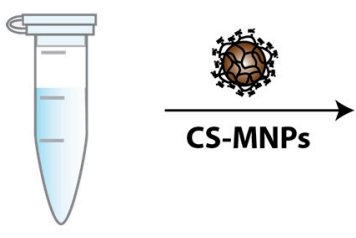

(b)
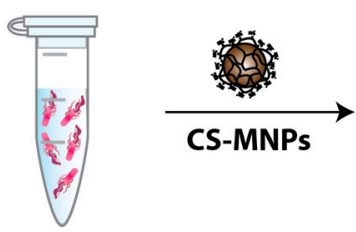
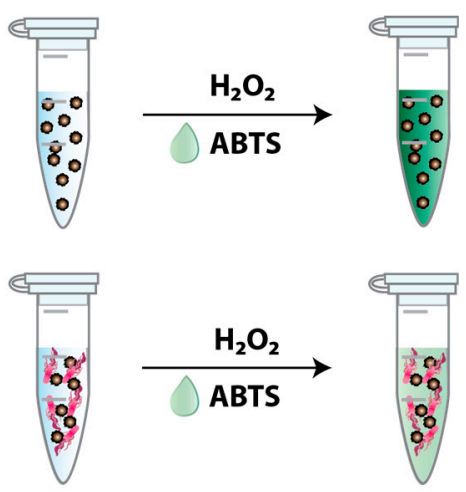

Figure 3. Schematic representation of the CS-MNPs-based colorimetric bacteria detection (a) in the absence or (b) in the presence of bacterial cells.

We first found out that CS-MNPs retained over $80 \%$ of the original peroxidase activity of bare MNPs (Figure S2), which was enough to produce a colorimetric response. As expected, the catalytic activity of CS-MNPs was significantly reduced in the presence of gram-negative E. coli (Figure 4a), probably because of the increased hindrance in the accessibility of the ABTS substrate to CS-MNPs. As E. coli concentration increased from $10^{1}$ to $10^{8} \mathrm{CFU} \mathrm{mL} \mathrm{mL}^{-1}$, the absorbance at $417 \mathrm{~nm}$ corresponding to the oxidized ABTS gradually decreased (Figure $4 \mathrm{~b}$ ). From the calibration plots, E. coli might be spectrometrically determined at concentrations as low as $10^{2} \mathrm{CFU} \mathrm{mL}{ }^{-1}$ with a linear range from $10^{2}$ to $10^{6} \mathrm{CFU} \mathrm{mL} \mathrm{m}^{-1}$ (Figure 4c). Even without any detection instrument, the presence of E. coli in the sample solution could be visibly discriminated by the naked eye at $10^{4} \mathrm{CFU} \mathrm{mL} \mathrm{m}^{-1}$. When we used bare MNPs rather than CS-MNPs for the same E. coli detection experiments, their peroxidase activity was not efficiently inhibited by the presence of bacterial cells, probably due to the inefficient binding between bacteria and MNPs, and furthermore, there were significant variations in the absorbance, which made bacterial quantification difficult (Figure 4d).
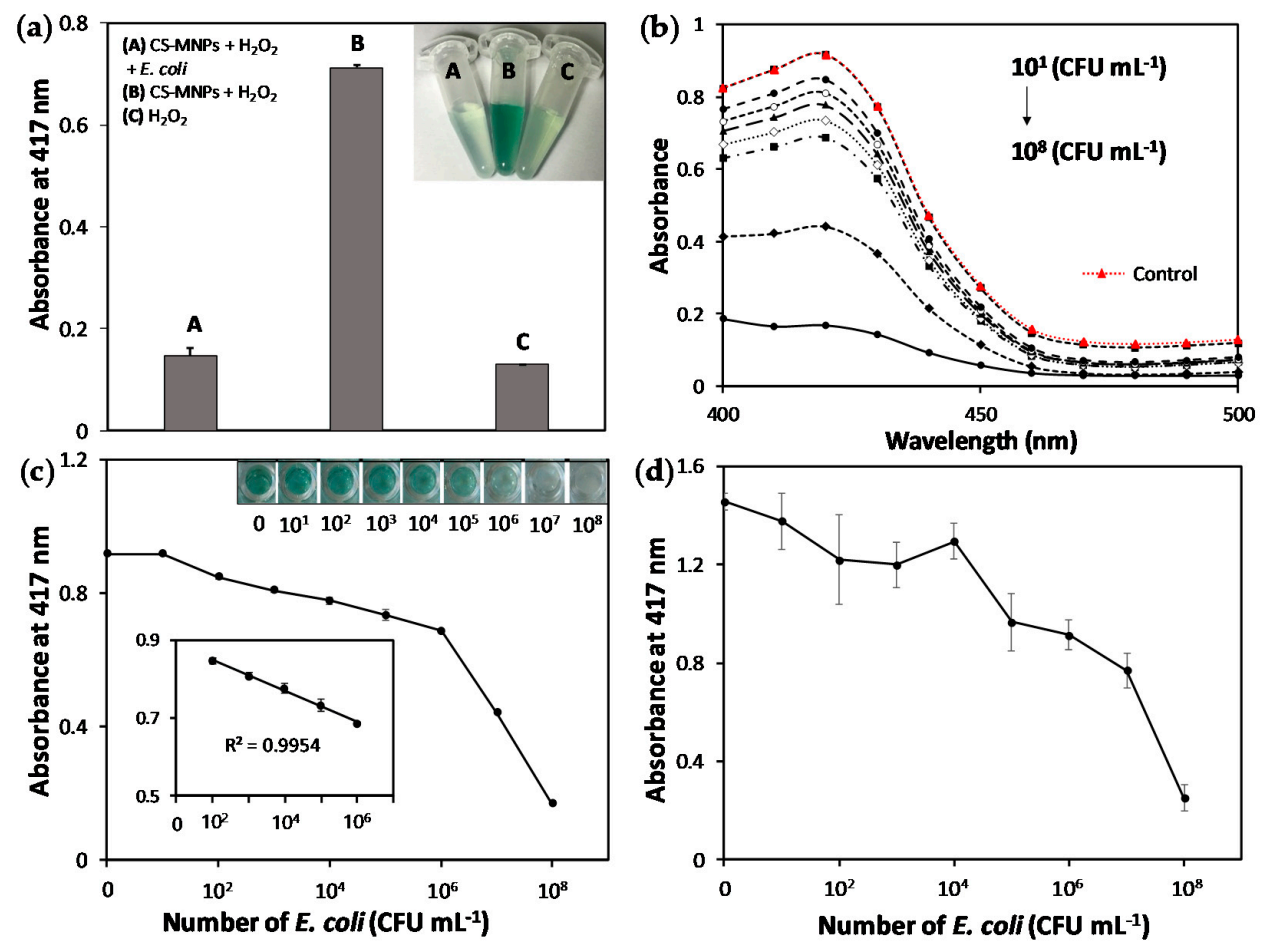

Figure 4. (a) Absorption intensity of the reaction leading to ABTS oxidation using CS-MNPs in the presence or absence of $E$. coli $\left(10^{8} \mathrm{CFU} \mathrm{mL} \mathrm{m}^{-1}\right)$. Real photograph of the reaction solution is shown in the 
inset; (b) Absorption spectra of the reaction tube at various E. coli concentrations ranging from $10^{1}$ to $10^{8} \mathrm{CFU} \mathrm{mL} \mathrm{mL}^{-1}$. (c) Absorption intensity of solutions obtained from the CS-MNPs-based assay at various E. coli concentrations. Real photograph of the reaction solution is shown in the inset; (d) Absorption intensity of solutions obtained from the bare MNPs-based assay at various E. coli concentrations.

Although chitosan has a higher affinity toward gram-positive bacteria than to gram-negative ones due to their relatively higher positive charge density, our CS-MNPs-based colorimetric bacteria detection resulted in similar sensitivity for both types of bacteria [36,37]. Absorbance $(417 \mathrm{~nm})$ was also significantly decreased in the presence of gram-positive $S$. aureus due to their binding-mediated inhibition of CS-MNPs' peroxidase activity (Figure 5a). Gradually reduced colorimetric signals were also produced from the samples containing increased S. aureus concentrations ranging from $10^{1}$ to $10^{8} \mathrm{CFU} \mathrm{mL}{ }^{-1}$ (Figure 5b). The linear range was established from $10^{2}$ to $10^{6} \mathrm{CFU} \mathrm{mL}^{-1}$ and the limit of detection was determined as $10^{2} \mathrm{CFU} \mathrm{mL}^{-1}$ (Figure $5 \mathrm{c}$ ). Similarly, S. aureus cells at $10^{4} \mathrm{CFU} \mathrm{mL}^{-1}$ were discriminated from the control sample without bacteria by the naked eye. With the bare MNPs, although peroxidase activity was marginally inhibited at concentrations over $10^{6} \mathrm{CFU} \mathrm{mL}^{-1}$, there were large variations in the absorbance, which was not suitable for bacterial quantification (Figure 5d).
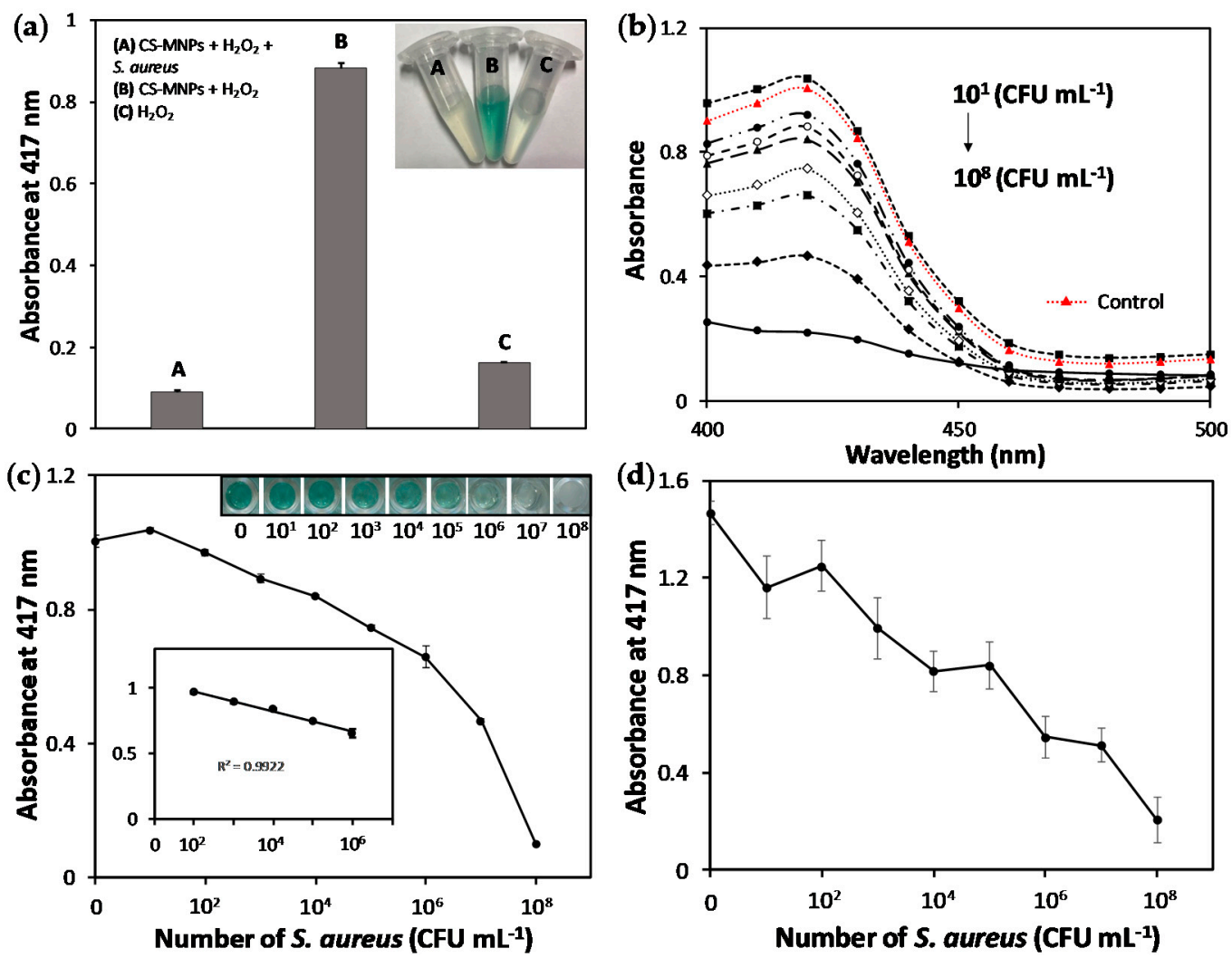

Figure 5. (a) Absorption intensity of the reaction leading to ABTS oxidation using CS-MNPs in the presence or absence of $S$. aureus $\left(10^{8} \mathrm{CFU} \mathrm{mL}^{-1}\right)$. Real photograph of the reaction solution is shown in the inset; (b) Absorption spectra of the reaction tube at various $S$. aureus concentrations ranging from $10^{1}$ to $10^{8} \mathrm{CFU} \mathrm{mL} \mathrm{mL}^{-1}$; (c) Absorption intensity of solutions obtained from the CS-MNPs-based assay at various $S$. aureus concentrations. Real photograph of the reaction solution is shown in the inset; (d) Absorption intensity of solutions obtained from the bare MNPs-based assay at various S. aureus concentrations. 


\subsection{Demonstration of the Interaction between CS-MNPS and Bacteria}

We hypothesized that the electrostatic interaction between positively-charged CS-MNPs and negatively-charged bacteria explained the reduced colorimetric signal by hindering substrate accessibility to the CS-MNPs. To test the hypothesis, SEM analyses were conducted and the results showed the increased binding of CS-MNPs to bacteria compared to bare MNPs (Figure 6). In the case of bare MNPs, a lower number was detected on the surface of both E. coli and S. aureus indicating a relatively weak interaction between MNPs and bacteria. In contrast, CS-MNPs resulted in a much more efficient binding on the surface for both types of bacteria, showing a stronger attraction, mainly due to the protonated amine group of chitosan at acidic $\mathrm{pH}$ conditions with the anionic membrane of bacteria.

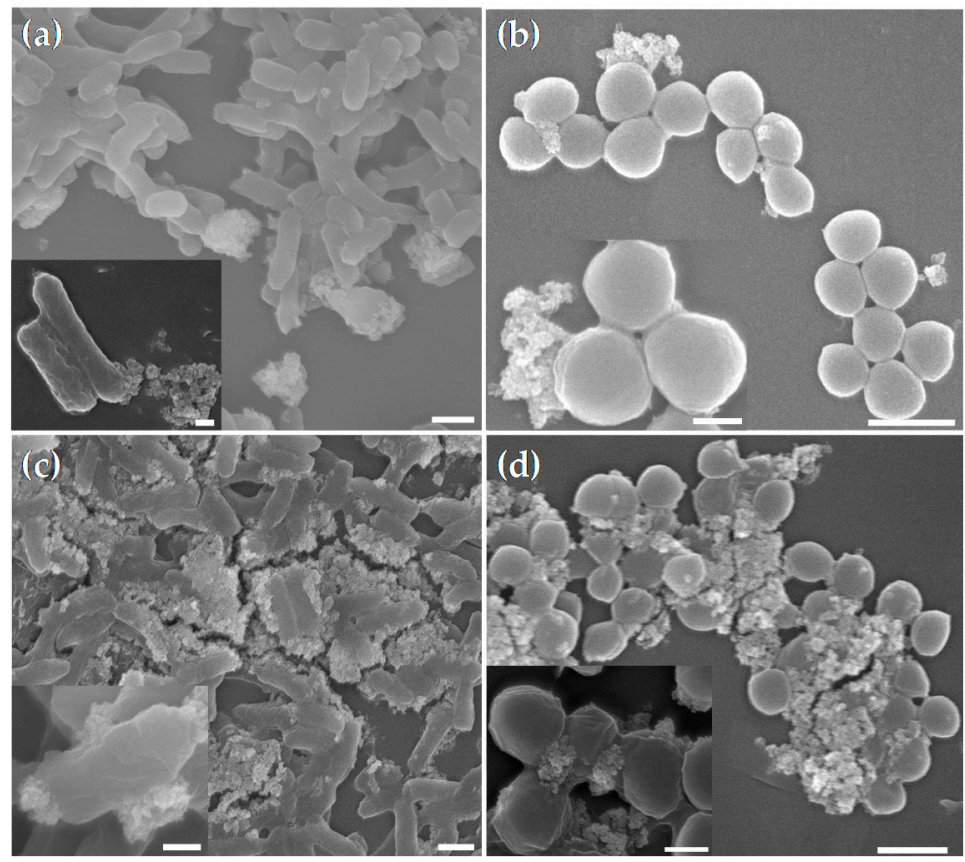

Figure 6. SEM images of (a) MNPs incubated with E. coli. (b) MNPs incubated with S. aureus. (c) CS-MNPs incubated with E. coli and (d) CS-MNPs incubated with S. aureus. Scale bars indicate $1 \mu \mathrm{m}$. In the insets, scale bars indicate $0.3 \mu \mathrm{m}$.

Surface zeta potentials of bacteria with or without MNPs and CS-MNPs were also analyzed to clearly understand the role of surface charge on the interaction between bacteria and nanoparticles (Figure 7). The surfaces of both bacterial strains were found to have a negative charge, as previously observed [36]. When bacteria were incubated with MNPs, the surface charges marginally increased but still had negative values, as bare MNPs showed slightly-positive zeta potentials. Finally, by incubating with CS-MNPs, the surface potential increased notably and yielded positive values for both bacterial strains, revealing the efficient binding of CS-MNPs to the surface of bacteria. As expected, both bacteria incubated with free CS without MNPs also showed notably increased surface zeta potentials, due to the effective interaction with positively-charged CS (Figure S3). This investigation demonstrated that positively-charged CS-MNPs effectively interacted with negatively-charged bacteria, which critically contributed to the reduced catalytic activity of CS-MNPs. 


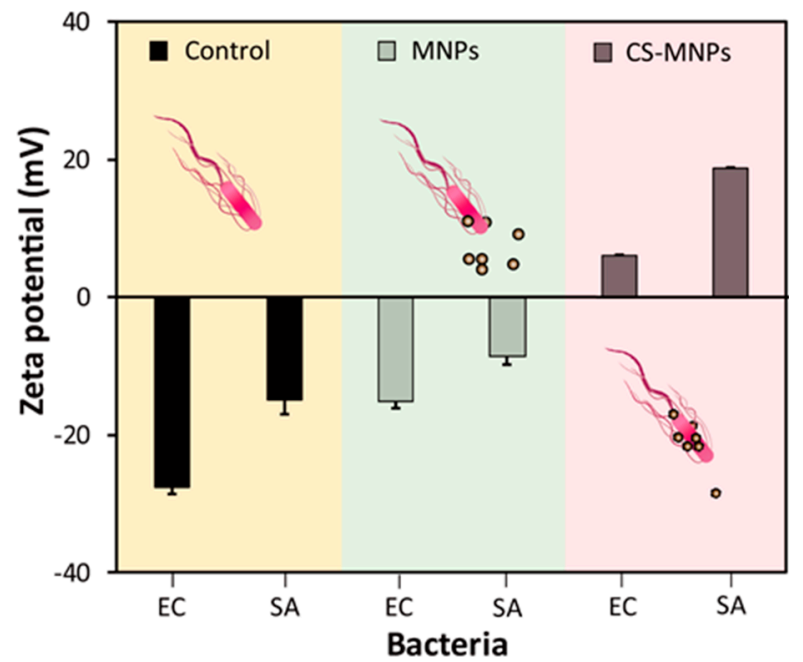

Figure 7. Zeta potential analyses of bacteria only, bacteria with bare MNPs, and bacteria with CS-MNPs. E. coli (EC) and S. aureus (SA) were used in the experiments.

\section{Conclusions}

In summary, a simple, rapid, inexpensive, and instrument-free colorimetric bacteria detection method has been successfully developed based on the efficient electrostatic interaction between CS-MNPs and bacterial cells, as well as the concomitant inhibition of the peroxidase activity of CS-MNPs. This assay can be conveniently conducted and analyzed by monitoring the green color reduction within $10 \mathrm{~min}$. Both gram-negative E. coli and gram-positive S. aureus were successfully quantified at concentrations as low as $10^{2} \mathrm{CFU} \mathrm{mL}{ }^{-1}$ spectrophotometrically and $10^{4} \mathrm{CFU} \mathrm{mL}^{-1}$ by the naked eye, which is compatible with the current clinical setup. Based on these observations, we anticipate that this colorimetric bacteria detection assay developed using the specific affinity and catalytic activity of CS-MNPs may provide a new way to detect broad-spectrum bacteria on site.

Supplementary Materials: The following figures are available online at http://www.mdpi.com/2079-4991/10/1/92/ s1, Figure S1: Zeta potential analyses of CS-MNPs prepared with different concentrations of chitosan, Figure S2: Comparison of the peroxidase-like activity between MNPs and CS-MNPs, Figure S3: Zeta potential analyses of free CS only, bacteria only, and bacteria with free CS. E. coli (EC) and S. aureus (SA) were used in the experiments.

Author Contributions: T.N.L.: Conceptualization, investigation, writing-original draft preparation. T.D.T.: Validation, writing-review and editing. M.I.K.: Conceptualization, supervision, writing-review and editing. All authors have read and agreed to the published version of the manuscript.

Funding: This work was supported by the Center for Research and Development of the Police Science and Technology grant funded by the Korea National Police Agency (KNPA) (PA-K000001-2019-401) and the National Research Foundation of Korea (NRF) grant funded by the Korea government (Ministry of Science and ICT (NRF-2019R1A2C1087459)).

Conflicts of Interest: The authors declare no conflict of interest.

\section{References}

1. Nataro, J.P.; Kaper, J.B. Diarrheagenic Escherichia coli. Clin. Microbiol. Rev. 1998, 11, 142-201. [CrossRef] [PubMed]

2. Twele, L.; Moyen, E.; Zhang, K.; Dalton, B.; Church, D.; Conly, J. Methicillin-resistant Staphylococcus aureus endocarditis and de novo development of daptomycin resistance during therapy. Can. J. Infect. Dis. Med. Microbiol. 2010, 21, 89-93. [CrossRef] [PubMed]

3. Lâm, T.-T.; Giese, B.; Chikkaballi, D.; Kühn, A.; Wolber, W.; Pané-Farré, J.; Schäfer, D.; Engelmann, S.; Fraunholz, M.; Sinha, B. Phagolysosomal integrity is generally maintained after Staphylococcus aureus invasion of nonprofessional phagocytes but is modulated by strain 6850. Infect. Immun. 2010, 78, 3392-3403. [CrossRef] [PubMed] 
4. Global Burden of Foodborne Diseases; WHO: Geneva, Switzerland, 2015.

5. Brooks, B.; Devenish, J.; Lutze-Wallace, C.; Milnes, D.; Robertson, R.; Berlie-Surujballi, G. Evaluation of a monoclonal antibody-based enzyme-linked immunosorbent assay for detection of Campylobacter fetus in bovine preputial washing and vaginal mucus samples. Vet. Microbiol. 2004, 103, 77-84. [CrossRef]

6. Heo, J.; Hua, S.Z. An overview of recent strategies in pathogen sensing. Sensors 2009, 9, 4483-4502. [CrossRef]

7. Zhu, L.; He, J.; Cao, X.; Huang, K.; Luo, Y.; Xu, W. Development of a double-antibody sandwich ELISA for rapid detection of Bacillus Cereus in food. Sci. Rep. 2016, 6, 16092. [CrossRef]

8. Alamer, S.; Eissa, S.; Chinnappan, R.; Herron, P.; Zourob, M. Rapid colorimetric lactoferrin-based sandwich immunoassay on cotton swabs for the detection of foodborne pathogenic bacteria. Talanta 2018, 185, 275-280. [CrossRef]

9. Paniel, N.; Baudart, J. Colorimetric and electrochemical genosensors for the detection of Escherichia coli DNA without amplification in seawater. Talanta 2013, 115, 133-142. [CrossRef]

10. Chen, J.; Alcaine, S.D.; Jackson, A.A.; Rotello, V.M.; Nugen, S.R. Development of engineered bacteriophages for Escherichia coli detection and high-throughput antibiotic resistance determination. ACS Sens. 2017, 2, 484-489. [CrossRef]

11. Sun, J.; Huang, J.; Li, Y.; Lv, J.; Ding, X. A simple and rapid colorimetric bacteria detection method based on bacterial inhibition of glucose oxidase-catalyzed reaction. Talanta 2019, 197, 304-309. [CrossRef]

12. Yuan, P.; Ding, X.; Yang, Y.Y.; Xu, Q.-H. Metal nanoparticles for diagnosis and therapy of bacterial infection. Adv. Healthc. Mater. 2018, 7, 1701392. [CrossRef] [PubMed]

13. Singh, P.; Kakkar, S.; Kumar, R.; Bhalla, V. Rapid and sensitive colorimetric detection of pathogens based on silver-urease interaction. Chem. Commun. 2019, 55, 4765-4768. [CrossRef] [PubMed]

14. Halas, N.J.; Lal, S.; Chang, W.-S.; Link, S.; Nordlander, P. Plasmons in strongly coupled metallic nanostructures. Chem. Rev. 2011, 111, 3913-3961. [CrossRef] [PubMed]

15. Jain, P.K.; Huang, X.; El-Sayed, I.H.; El-Sayed, M.A. Noble metals on the nanoscale: Optical and photothermal properties and some applications in imaging, sensing, biology, and medicine. Acc. Chem. Res. 2008, 41, 1578-1586. [CrossRef]

16. Verma, M.S.; Rogowski, J.L.; Jones, L.; Gu, F.X. Colorimetric biosensing of pathogens using gold nanoparticles. Biotechnol. Adv. 2015, 33, 666-680. [CrossRef]

17. Wu, S.; Duan, N.; Qiu, Y.; Li, J.; Wang, Z. Colorimetric aptasensor for the detection of Salmonella enterica serovar typhimurium using $\mathrm{ZnFe}_{2} \mathrm{O}_{4}$-reduced graphene oxide nanostructures as an effective peroxidase mimetics. Int. J. Food Microbiol. 2017, 261, 42-48. [CrossRef]

18. Gao, L.; Zhuang, J.; Nie, L.; Zhang, J.; Zhang, Y.; Gu, N.; Wang, T.; Feng, J.; Yang, D.; Perrett, S. Intrinsic peroxidase-like activity of ferromagnetic nanoparticles. Nat. Nanotechnol. 2007, 2, 577. [CrossRef]

19. Jv, Y.; Li, B.; Cao, R. Positively-charged gold nanoparticles as peroxidiase mimic and their application in hydrogen peroxide and glucose detection. Chem. Commun. 2010, 46, 8017-8019. [CrossRef]

20. Chen, J.; Andler, S.M.; Goddard, J.M.; Nugen, S.R.; Rotello, V.M. Integrating recognition elements with nanomaterials for bacteria sensing. Chem. Soc. Rev. 2017, 46, 1272-1283. [CrossRef]

21. Kwon, D.; Lee, S.; Ahn, M.M.; Kang, I.S.; Park, K.-H.; Jeon, S. Colorimetric detection of pathogenic bacteria using platinum-coated magnetic nanoparticle clusters and magnetophoretic chromatography. Anal. Chim. Acta 2015, 883, 61-66. [CrossRef]

22. Eltzov, E.; Marks, R.S. Colorimetric stack pad immunoassay for bacterial identification. Biosens. Bioelectron. 2017, 87, 572-578. [CrossRef] [PubMed]

23. Alamer, S.; Eissa, S.; Chinnappan, R.; Zourob, M. A rapid colorimetric immunoassay for the detection of pathogenic bacteria on poultry processing plants using cotton swabs and nanobeads. Mikrochim. Acta 2018, 185, 164. [CrossRef] [PubMed]

24. Sun, Q.; Zhao, G.; Dou, W. Blue silica nanoparticle-based colorimetric immunoassay for detection of Salmonella pullorum. Anal. Methods 2015, 7, 8647-8654. [CrossRef]

25. Park, J.Y.; Jeong, H.Y.; Kim, M.I.; Park, T.J. Colorimetric detection system for Salmonella typhimurium based on peroxidase-like activity of magnetic nanoparticles with DNA aptamers. J. Nanomater. 2015, $2015,2$. [CrossRef]

26. Luo, K.; Jeong, K.B.; You, S.M.; Lee, D.H.; Jung, J.Y.; Kim, Y.R. Surface-engineered starch magnetic microparticles for highly effective separation of a broad range of bacteria. ACS Sustain. Chem. Eng. 2018, 6, 13524-13531. [CrossRef] 
27. Lu, A.H.; Salabas, E.E.L.; Schüth, F. Magnetic nanoparticles: Synthesis, protection, functionalization, and application. Angew. Chem. Int. Ed. 2007, 46, 1222-1244. [CrossRef]

28. Safari, J.; Javadian, L. Chitosan decorated $\mathrm{Fe}_{3} \mathrm{O}_{4}$ nanoparticles as a magnetic catalyst in the synthesis of phenytoin derivatives. RSC Adv. 2014, 4, 48973-48979. [CrossRef]

29. Juang, R.-S.; Shiau, R.-C. Metal removal from aqueous solutions using chitosan-enhanced membrane filtration. J. Membr. Sci 2000, 165, 159-167. [CrossRef]

30. Konwar, A.; Chowdhury, D.; Dan, A. Chitosan based in situ and ex situ magnetic iron oxide nanoparticles for rapid endotoxin removal from protein solutions. Mater. Chem. Front. 2019, 3, 716-725. [CrossRef]

31. Cheon, H.J.; Adhikari, M.D.; Chung, M.; Tran, T.D.; Kim, J.; Kim, M.I. Magnetic nanoparticles-embedded enzyme-inorganic hybrid nanoflowers with enhanced peroxidase-like activity and substrate channeling for glucose biosensing. Adv. Healthc. Mater. 2019, 8, 1801507. [CrossRef]

32. Katas, H.; Hussain, Z.; Ling, T.C. Chitosan nanoparticles as a percutaneous drug delivery system for hydrocortisone. J. Nanomater. 2012, 2012, 45. [CrossRef]

33. Rao, K.K.; Rao, K.M.; Kumar, P.N.; Chung, I.-D. Novel chitosan-based pH sensitive micro-networks for the controlled release of 5-fluorouracil. Iran. Polym. J. 2010, 19, 265-276.

34. Vijayalekshmi, V;; Khastgir, D. Eco-friendly methanesulfonic acid and sodium salt of dodecylbenzene sulfonic acid doped cross-linked chitosan based green polymer electrolyte membranes for fuel cell applications. J. Membr. Sci. 2017, 523, 45-59. [CrossRef]

35. Silva, V.; Andrade, P.; Silva, M.; Valladares, L.D.L.S.; Aguiar, J.A. Synthesis and characterization of $\mathrm{Fe}_{3} \mathrm{O}_{4}$ nanoparticles coated with fucan polysaccharides. J. Magn. Magn. Mater 2013, 343, 138-143. [CrossRef]

36. Jia, X.; Ahmad, I.; Yang, R.; Wang, C. Versatile graphene-based photothermal nanocomposites for effectively capturing and killing bacteria, and for destroying bacterial biofilms. J. Mater. Chem. B 2017, 5, 2459-2467. [CrossRef]

37. Zhang, W.; Shi, S.; Wang, Y.; Yu, S.; Zhu, W.; Zhang, X.; Zhang, D.; Yang, B.; Wang, X.; Wang, J. Versatile molybdenum disulfide based antibacterial composites for in vitro enhanced sterilization and in vivo focal infection therapy. Nanoscale 2016, 8, 11642-11648. [CrossRef]

(C) 2020 by the authors. Licensee MDPI, Basel, Switzerland. This article is an open access article distributed under the terms and conditions of the Creative Commons Attribution (CC BY) license (http://creativecommons.org/licenses/by/4.0/). 